\title{
Method development, degradation pathway and kinetic of capecitabine
}

\author{
Dhara R. Patel
}

Student, Institute of Research and Development, Gujarat Forensic Sciences University, Gandhinagar, Gujarat, India

*Corresponding Author: Dhara R. Patel

Email: dhare2020@gmail.com

\begin{abstract}
The present work describes a simple, accurate and precise Stability indicating RP-HPLC method for the estimation of Capecitabine (CPT) in bulk and pharmaceutical formulation. The Mobile phase used was Acetonitrile: Water (60: 40v/v) with $1 \mathrm{ml} / \mathrm{min}$. flow rate and $240 \mathrm{~nm}$ was used as a wavelength maximum. The C18 HS (250 X 4.6) mm, $5 \mu \mathrm{m}$ column was used as a stationary phase. The method was validated as per the ICHQ2 Guidelines. The retention time of CPT was found to be 3.3 min. A linear response was observed in the range of $10-50 \mu \mathrm{g} / \mathrm{mL}$ with a regression coefficient of 0.999 . The LOD and LOQ were found to be $1.43 \mu \mathrm{g} / \mathrm{mL}$ and $4.34 \mu \mathrm{g} / \mathrm{mL}$ respectively. This method can be used for the determination of CPT in quality control of API and dosage form without interference of the excipients, impurities and degradation products and hence can be used as stability indicating assay method. CPT was subjected to degradation under different stress conditions recommended by ICH viz acid, alkali, photolytic, dry heat and oxidative condition. The samples so generated were used for degradation studies including degradation kinetic study using the developed method. The degradation pathway of CPT was found to be acid hydrolysis and temperature exceeding $100^{\circ} \mathrm{c}$. The degradation kinetic study shows that the acid hydrolysis, alkaline hydrolysis and oxidative degradation of the CPT follow first order kinetic.
\end{abstract}

Keywords: Anticancer drug, Capecitabine, Degradation, Stability indicating assay method, Validation.

\section{Introduction}

Capecitabine is a fluoropyrimidine carbamate, anti metabolite class of antineoplastic drug. Chemically it is 5'-deoxy-5-fluoro-N-[(pentyloxy) carbonyl] - cytidine with empirical formula of $\mathrm{C} 15 \mathrm{H} 22 \mathrm{FN} 3 \mathrm{O} 6$ and the molecular weight of $359.35 \mathrm{~g} / \mathrm{mol}^{1}$. It is used to treat cancer of the colorectal, breast and stomach and oesophagus.

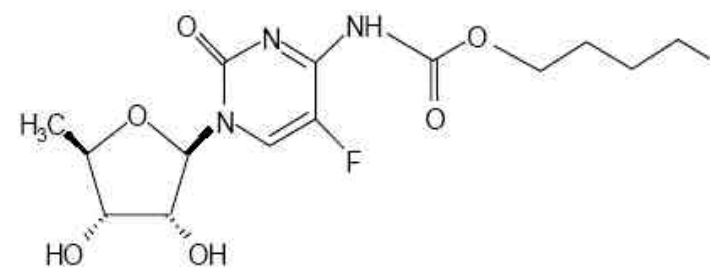

Fig. 1: Structure of the CPT

The degradation product is defined as a chemical change in the drug substance and drug product brought about over time and/or by action of various environmental conditions like light, temperature, $\mathrm{pH}$, water or by reaction with an excipient and/or the immediate container/closure system. Stress testing helps to determine intrinsic stability of molecule by establishing degradation pathway in order to identify degradation products and to validate stability indicating power of analytical method. ${ }^{2}$ Submission of data from stress testing the drug substance using acid and base hydrolysis, temperature, photolysis and oxidation is recommended..$^{3-4}$ A Stability indicating method is defined as a validated analytical procedure that accurate and precisely measure active ingredients (drug substance or drug product) free from process impurities, excipients and degradation product. $^{5}$ The FDA recommends that all assay procedures for stability should be stability indicating. It represents also a powerful tool when investigating out-of-trend (OOT) ${ }^{6}$ or out-of specification (OOS) result ${ }^{7}$ in quality control processes. $^{8}$

Validation is a process that determines the fitness of an assay, which has been properly developed, optimised and standardized, for an intended purpose. Results from method validation can be used to judge the quality, reliability and consistency of analytical results. ${ }^{9-10}$

The study of drug degradation kinetics is of greater importance for development of stable formulation and establishment of expiration date for commercially available drug products. The degradation rate kinetic gives the information regarding the rate of process that generally leads to the inactivation of drug through either decomposition or loss of drug by conversion to a less favourable physical or chemical form. The order of a reaction is determined by three methods: Substitution method, Graphical method and half life method. ${ }^{11-13}$

There are many Analytical techniques including U.V Spectrophotometric methods, ${ }^{14-16}$ HPLC methods, ${ }^{16-22}$ HPTLC method ${ }^{23}$ and Stability indicating RP-HPLC $^{24}$ are reported for determination of CPT. There was not reported stability indicating RP-HPLC method along with degradation kinetic study for CPT, thus it was thought of interest to develop and validate Stability indicating assay method for determination of CPT in the presence of degradant products and to perform degradation kinetic study of CPT. 


\section{Materials and Methods}

Chemicals and Reagents: CPT reference standard was received from west coast pharma, Ahmadabad. CPT Tablets with label claim of $500 \mathrm{mg}$ were received from Intas pharmaceutical, Ahmadabad as a gift sample. Sodium hydroxide, hydrochloric acid and hydrogen Peroxide of AR Grade are purchased from Finar. HPLC grade water was prepared in lab by distillation Millipore water and then filtered through $0.4 \mathrm{~mm}$ filter. HPLC grade Acetonotril was purchased from SRL.

Instruments Used in Method Development: The instrument used was Jasco Net LC- II/ADC with U.V detector and Chrom NAV software. Other instruments used are UV-Visible Spectrophotometer V-630, electronic analytical weighing balance (LC/GC-Axis), Digital Ultra Sonicator (CD4820 Hintron instrument), Hot air oven (Lab top instrument Pvt. Ltd.), and UV chamber.

\section{RP-HPLC Method Development for CPT}

Selection of Chromatographic Parameters

Chromatographic Mode: Reverse phase HPLC

Stationary Phase: C18 HS (250 X 4.6) mm, $5 \mu \mathrm{m}$. bonded phase

Mobile Phase: Acetonitril: water (60:40).

Detector and Detection Wavelength: UV-Visible detector and $240 \mathrm{~nm}$ as detection wavelength.

Flow rate: $1 \mathrm{ml} / \mathrm{min}$

Injection volume: $20 \mu \mathrm{L}$

Preparation of Calibration Curve of Capecitabine (API): Capecitabine solutions having concentration 10, $20,30,40$ and $50 \mu \mathrm{g} / \mathrm{ml}$ were prepared. The samples were injected in the HPLC using the mobile phase. The calibration curve of Concentration $(\mu \mathrm{g} / \mathrm{mL})$ vs. Area was plotted and correlation coefficient, regression line equations, $y$-intercept and slope of the regression line for CPT were determined.

\section{Validation Studies of HPLC Method}

Specificity: The analyte should have no interference from other extraneous components and be well resolved from them. Specificity is the procedure to detect quantitatively the analyte in presence of component that may be expected to be present in the sample matrix.

System Suitability: System suitability test was carried out to verify that the analytical system is working properly to give accurate and precise results. Standard solution $(20 \mu \mathrm{g} / \mathrm{mL})$ was injected six times and the chromatograms were recorded and evaluated for various parameters like number of theoretical plates, symmetry factor and resolution (if applicable).

Linearity: Analyte concentrations in the range of 10$50 \mu \mathrm{g} / \mathrm{ml}$ were prepared. A graph of Concentration $(\mu \mathrm{g} / \mathrm{mL})$ vs. Area was plotted and the regression coefficient ' $\mathrm{r}^{2}$ ', $y$-intercept and slope of the regression were calculated.

Limit of Detection: The LOD was estimated from the set of 3 calibration curves used to determine linearity of the method. LOD was determined using following formula:

\section{$\mathrm{LOD}=3.3 * \sigma / \mathrm{S}$}

Where, $\sigma=$ the standard deviation of $y$-intercepts of regression lines, $\mathrm{S}=$ the slope of the calibration curve.

Limit of Quantification: The LOD was estimated from the set of 3 calibration curves used to determine linearity of the method. LOD was determined using following formula:

$$
\text { LOQ }=10 * \sigma / S
$$

Where, $\sigma=$ the standard deviation of $y$-intercepts of regression lines, $\mathrm{S}=$ the slope of the calibration curve.

Accuracy (By Recovery Study): The accuracy of the method was determined by spiking different concentrations of pure drug in the pre-analyzed samples within the analytical concentration range of the proposed method at three different levels of $80 \%, 100 \%$ and $120 \%$. The solutions were prepared in triplicates. The amount of CPT was calculated at each level and \% recovery was determined.

\section{Precision}

Intraday Precision: In intraday variation study, three different concentration of the standard from the linearity range, that is $20 \mu \mathrm{g} / \mathrm{ml}, 30 \mu \mathrm{g} / \mathrm{ml}$ and $40 \mu \mathrm{g} / \mathrm{ml}$ were prepared from the stock solution $(100 \mu \mathrm{g} / \mathrm{mL})$ and analyzed at three times in a day i.e. morning, afternoon and evening and the area was noted.

Interday Precision: Intraday precision was assessed by analyzing the standard solution of $20 \mu \mathrm{g} / \mathrm{ml}, 30 \mu \mathrm{g} / \mathrm{ml}$ and $40 \mu \mathrm{g} / \mathrm{ml}$ for three consecutive days at three times in a day i.e. morning, afternoon and evening and the area was noted.

Robustness: The robustness of an analytical method was carried out to confirm that the method remained unaffected by small but deliberate variations in method parameters. The standard solution was injected five times for each varied conditions of flow, column temperature, $\mathrm{pH}$, and mobile phase ratio and chromatograms were recorded.

Ruggedness: It is a degree of reproducibility of test results obtained by the analysis of the samples under a variety of normal test conditions such as different laboratories, different analyst, different instrument, etc. Ruggedness of the method was determined by carrying out the analysis by two different analysts and the respective area was noted.

Assay of Capecitabine Tablets: Desired concentration of $20 \mu \mathrm{g} / \mathrm{mL}$ was prepared. This solution was then analysed in HPLC and from the area found, the amount of the drug was calculated.

Degradation Profile of Capecitabine by HPLC: Solution of $200 \mu \mathrm{g} / \mathrm{mL}$ was prepared and kept at room temperature in dark place for 5 hour for acid hydrolysis, alkaline hydrolysis and for oxidative condition. 
The order of the reaction was calculated from the slope of the Log C vs. Time graph.

Stress Degradation by Acid Hydrolysis using $0.1 \mathrm{~N}$ HCL: After degradation, $1 \mathrm{ml}$ of degraded solution was withdrawn and transferred in $10 \mathrm{ml}$ volumetric flask and excess of Acid was neutralised with the $0.1 \mathrm{~N}$ $\mathrm{NaOH}$ (Check with the $\mathrm{pH}$ paper) and then dilute up to the mark with diluents $(20 \mu \mathrm{g} / \mathrm{mL})$ and this solution was then analysed in RP-HPLC.

For the degradation kinetic study the sample was withdrawn at $0-5 \mathrm{hr}$ of time interval and neutralised with $0.1 \mathrm{~N} \mathrm{NaOH}$, diluted with diluents and analysed and from the area found, concentration, Log conc. and $\%$ degradation were calculated for each time interval and then Log C. Vs. Time graph was plotted.

Stress Degradation by Alkaline Hydrolysis using 0.1N NaOH: After degradation, $1 \mathrm{ml}$ of degraded solution was withdrawn and transferred in $10 \mathrm{~mL}$ volumetric flask and excess of base was neutralised with the $0.1 \mathrm{~N} \mathrm{HCL}$ (Check with the $\mathrm{pH}$ paper) and then dilute up to the mark with diluents $(20 \mu \mathrm{g} / \mathrm{mL})$ and this solution was then analysed in RP-HPLC.

For the degradation kinetic study the sample was withdrawn at $0-5 \mathrm{hr}$ of time interval and neutralised with $0.1 \mathrm{~N} \mathrm{HCL}$, diluted with diluents and analysed and from the area found, concentration, Log conc. and \% degradation were calculated for each time interval and then Log C Vs. Time graph was plotted.

Stress Degradation under Oxidative Condition using 3\% H2O2: After degradation, $20 \mu \mathrm{g} / \mathrm{mL}$ of solution was prepared and this solution was then analysed in RP-HPLC.

For the degradation kinetic study the sample was withdrawn at $0-5 \mathrm{hr}$ of time interval and diluted with diluents and analysed and from the area found, concentration, Log conc. and \% degradation were calculated for each time interval and then $\log \mathrm{C}$ vs. Time graph was plotted.
Stress Degradation under Photolytic Condition using UV Light at 366nm: $50 \mathrm{mg}$ of CPT was placed in a Petri dish and exposed to UV light at $366 \mathrm{~nm}$ under U.V chamber for 7 days. After this exposure, $25 \mathrm{mg}$ powder was accurately weighed, and transferred into 25 $\mathrm{mL}$ volumetric flask, add few $\mathrm{mL}$ of water and sonicate for $5 \mathrm{~min}$. and then diluted up to the mark with diluents $(1000 \mu \mathrm{g} / \mathrm{mL})$ (Note: In case of tablet, filter the solution with whatman filter paper no.42). From this solution, $0.2 \mathrm{~mL}$ was taken and diluted up to $10 \mathrm{~mL}$ with diluents $(20 \mu \mathrm{g} / \mathrm{mL})$ and then analyzed.

Stress Degradation under Dry Heat Condition using Hot Air Oven at $60^{\circ}$ c: $50 \mathrm{mg}$ of CPT was placed in a Petri dish and exposed to dry heat under hot air oven at $60^{\circ} \mathrm{c}$ for 1day. After this exposure, $25 \mathrm{mg}$ powder was accurately weighed, and transferred into $25 \mathrm{~mL}$ volumetric flask, add few $\mathrm{mL}$ of water and sonicate for $5 \mathrm{~min}$. and then diluted up to the mark with distilled water $(1000 \mu \mathrm{g} / \mathrm{mL})$ (Note: In case of tablet, filter the solution with whatman filter paper no.42). From this solution, $0.2 \mathrm{~mL}$ was taken and diluted up to $10 \mathrm{~mL}$ with diluents $(20 \mu \mathrm{g} / \mathrm{mL})$ and then analysed.

\section{Results and Discussion Method Validation}

1. Specificity: There was no interference in the peaks due to diluents. The area and the peak of the standard and sample were almost similar which means that there was no interference of the excipient in the analysis of the drug.

2. System Suitability: The column efficiency (Number of theoretical plates) is NLT 2000 theoretical plates and the tailing factor is NMT 2.0. The relative standard deviation for standard six replicate is not more than 2.0. Hence the developed method was suitable for analysis.

\section{Linearity, LOD and LOQ}

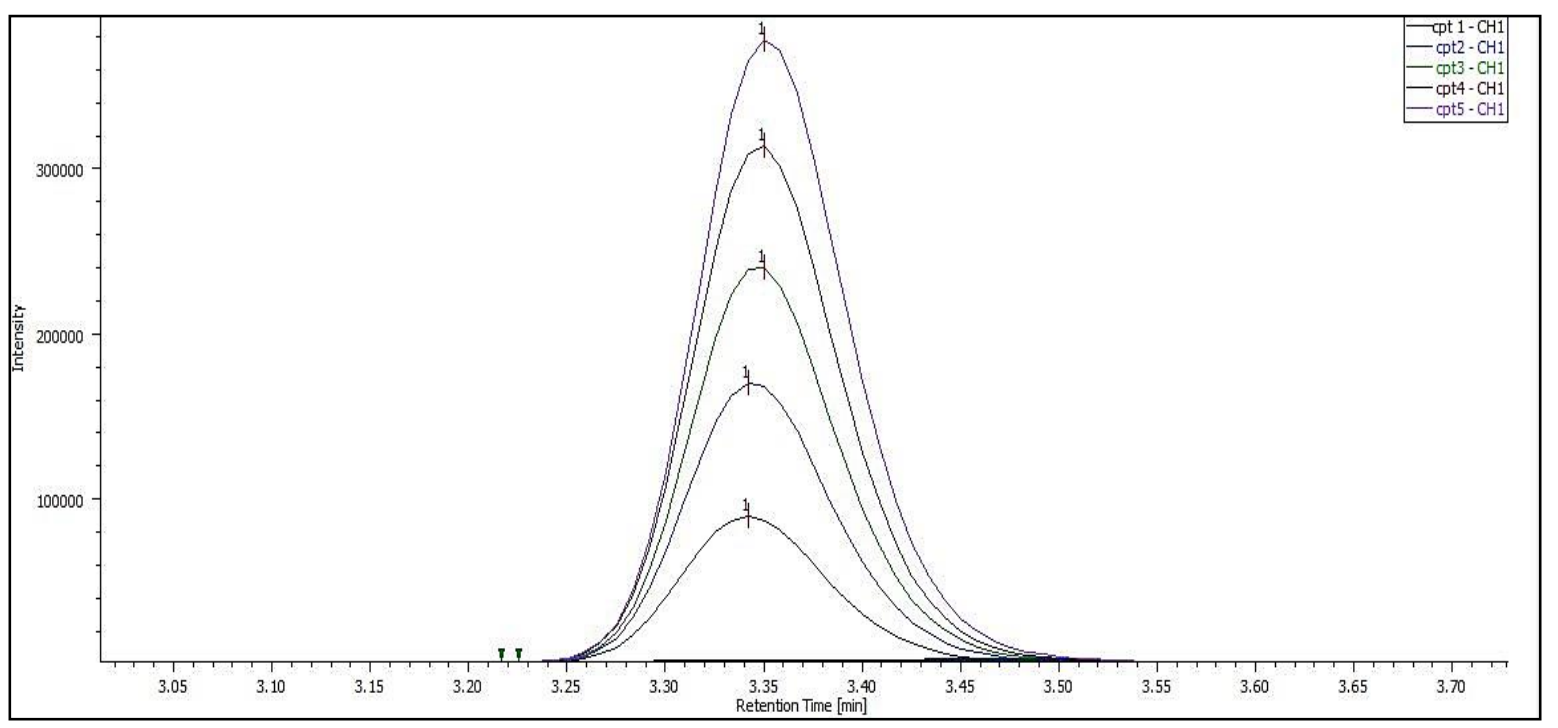

Fig. 2: Overlay chromatogram of CPT 
The correlation coefficient value was found to be 0.9996. The area obtained was directly proportional to the concentration of analyte in the sample. The method can, therefore be termed as linear in the specified range. Based on the linearity results, the working range of the method can be established as $10 \%$ to $50 \%$ of the working concentration. The LOD and LOQ were found to be $1.43 \mu \mathrm{g} / \mathrm{mL}$ and $4.34 \mu \mathrm{g} / \mathrm{mL}$ respectively, which indicates the sensitivity of method, is sufficient. Overlay chromatogram of CPT of $10-50 \mu \mathrm{g} / \mathrm{mL}$ is shown in the Fig. 2.

Accuracy: The \% Recovery for CPT was found to be $99.13 \%$ which comply with the standard limit given in the I.P (98-102\%) and USP (98-102\%) hence the method was accurate. It complies with IP and USP limits.

Precision: In interday and intraday precision study, the $\%$ R.S.D was found to be 1.04 and 1.03 respectively which comply with the standard limit $(\% \mathrm{RSD}<2 \%)$. Precision study shows the minor variation in the analysis of the CPT; hence the developed method was precise.

\section{Robustness \\ Change in Flow rate $( \pm \mathbf{1 0 \%})$}

In robustness study the \% RSD was found to be within limit (NMT 2\%) hence the method is unaffected by small deliberate change in flow rate and mobile phase ratio.

Ruggedness: In Ruggedness study the \% RSD was found to be within limit (NMT 2\%) hence the method is unaffected by different analyst.

Assay of Capecitabine Tablet: The \% Assay of capecitabine tablet was found to be $98.39 \%$ which comply with the standard limit given in the I.P 2010 (90-110\%) and USP 2010 (93-105\%).

\section{Result \& Discussion of Degradation Studies}

Comparative force degradation study of Capecitabine bulk drug and Pharmaceutical formulation by RP-HPLC: The degraded product peaks were well resolved from the pure drug peak with significant difference in their retention time.

\section{Acid-induced Degradation}

Table 1: Result of acid degradation of CPT bulk drug and marketed formulation

\begin{tabular}{|c|c|c|c|c|c|}
\hline S. No. & Product name & $\begin{array}{l}\text { Retention time } \\
\text { (min) }\end{array}$ & $\begin{array}{c}\text { Area } \\
(\mu \mathrm{V} \text { sec })\end{array}$ & $\%$ Degradation & Inference \\
\hline \multirow[t]{4}{*}{1} & Untreated Standard & 3.342 & 906348 & \multirow[t]{4}{*}{42.82} & \multirow{4}{*}{$\begin{array}{l}\text { Decrease in area and two } \\
\text { added peak found }\end{array}$} \\
\hline & Treated CPT & 3.108 & 518257 & & \\
\hline & DP 1 & 1.967 & 28382 & & \\
\hline & DP 2 & 2.300 & 85901 & & \\
\hline \multirow[t]{4}{*}{2} & Untreated Test & 3.342 & 872061 & \multirow[t]{4}{*}{26.34} & \multirow{4}{*}{$\begin{array}{c}\text { Decrease in area and two } \\
\text { added peak found }\end{array}$} \\
\hline & Treated test CPT & 3.108 & 642360 & & \\
\hline & DP 1 & 1.975 & 30372 & & \\
\hline & DP 2 & 2.300 & 36051 & & \\
\hline
\end{tabular}

Note- DP: Degradation product, Standard: Capecitabine API, Test: Capecitabine marketed formulation

\section{Alkali -induced Degradation}

Table 2: Result of alkaline degradation of CPT bulk drug and marketed formulation

\begin{tabular}{|c|c|c|c|c|c|}
\hline S. No. & Product name & $\begin{array}{l}\text { Retention time } \\
\text { (min) }\end{array}$ & $\begin{array}{c}\text { Area } \\
(\mu \mathrm{V} \text { sec })\end{array}$ & \%Degradation & Inference \\
\hline \multirow[t]{3}{*}{1} & $\begin{array}{l}\text { Untreated } \\
\text { Standard }\end{array}$ & 3.342 & 906348 & \multirow[t]{3}{*}{12.77} & \multirow[t]{3}{*}{$\begin{array}{l}\text { Decrease in area and one } \\
\text { added peak found }\end{array}$} \\
\hline & Treated CPT & 3.108 & 790537 & & \\
\hline & DP 1 & 1.967 & 55981 & & \\
\hline \multirow[t]{3}{*}{2} & Untreated Test & 3.342 & 872061 & \multirow[t]{3}{*}{12.78} & \multirow{3}{*}{$\begin{array}{l}\text { Decrease in area and one } \\
\text { added peak found }\end{array}$} \\
\hline & Treated test CPT & 3.108 & 760537 & & \\
\hline & DP 1 & 1.975 & 39288 & & \\
\hline
\end{tabular}




\section{Oxidative Degradation}

Table 3: Result of oxidative degradation of CPT bulk drug and marketed formulation

\begin{tabular}{|c|c|c|c|c|c|}
\hline S. No. & Product name & $\begin{array}{l}\text { Retention time } \\
\text { (min) }\end{array}$ & $\begin{array}{c}\text { Area } \\
(\mu \mathrm{V} \text { sec })\end{array}$ & \%Degradation & Inference \\
\hline \multirow[t]{5}{*}{1} & Untreated Standard & 3.342 & 906348 & \multirow[t]{5}{*}{20.84} & \multirow{5}{*}{$\begin{array}{l}\text { Decrease in area and three } \\
\text { added peak found }\end{array}$} \\
\hline & Treated CPT & 3.108 & 717434 & & \\
\hline & DP 1 & 1.233 & 24362 & & \\
\hline & DP 2 & 1.792 & 28901 & & \\
\hline & DP 3 & 2.492 & 961922 & & \\
\hline \multirow[t]{5}{*}{2} & Untreated Test & 3.342 & 872061 & \multirow[t]{5}{*}{17.15} & \multirow{5}{*}{$\begin{array}{l}\text { Decrease in area and two } \\
\text { added peak found }\end{array}$} \\
\hline & Treated test CPT & 3.108 & 722420 & & \\
\hline & DP 1 & 1.775 & 28276 & & \\
\hline & DP 2 & 2.492 & 1040228 & & \\
\hline & DP 3 & 3.342 & 872061 & & \\
\hline
\end{tabular}

Thermal Degradation

Table 4: Result of thermal degradation of CPT bulk drug and marketed formulation

\begin{tabular}{|l|c|c|c|c|c|}
\hline S. No. & Product name & $\begin{array}{c}\text { Retention time } \\
(\mathbf{m i n})\end{array}$ & $\begin{array}{c}\text { Area } \\
(\boldsymbol{\mu V} \mathbf{~ s e c})\end{array}$ & \%Degradation & Inference \\
\hline \multirow{2}{*}{1} & Untreated Standard & 3.342 & 906348 & \multirow{2}{*}{9.11} & Decrease in area \\
\cline { 2 - 4 } & Treated CPT & 3.350 & 823751 & & Decrease in area \\
\hline 2 & Untreated Test & 3.342 & 872061 & 3.30 & \\
\cline { 2 - 4 } & Treated test CPT & 3.350 & 843219 & & \\
\hline
\end{tabular}

\section{Photo Degradation}

Table 5: Result of Photolytic Degradation of CPT bulk drug and marketed formulation

\begin{tabular}{|l|c|c|c|c|c|}
\hline \multirow{2}{*}{ S. No. } & Product name & $\begin{array}{c}\text { Retention time } \\
(\mathbf{m i n})\end{array}$ & $\begin{array}{c}\text { Area } \\
(\boldsymbol{\mu V ~ s e c})\end{array}$ & \%Degradation & Inference \\
\hline \multirow{2}{*}{1} & Untreated Standard & 3.342 & 906348 & \multirow{2}{*}{4.90} & Decrease in area \\
\cline { 2 - 4 } & Treated CPT & 3.350 & 861908 & & Decrease in area \\
\hline 2 & Untreated Test & 3.342 & 872061 & 1.53 & \\
\cline { 2 - 4 } & Treated test CPT & 3.325 & 858687 & & \\
\hline
\end{tabular}

Degradation Kinetic Study

Degradation kinetic study under acidic condition, 0.1 N HCl

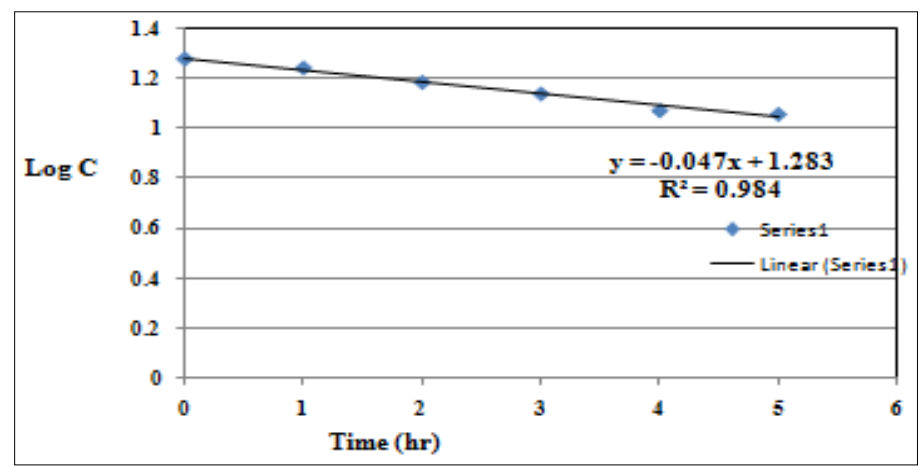

Fig. 3: $\log C$ vs. time graph for acid hydrolysis degradation 
Degradation kinetic study of bulk drug under acidic condition at room temperature showed that the decrease in area as compared to untreated drug for each sample withdrawn at $0-5 \mathrm{hr}$. The plot of $\log \mathrm{C}$ vs. time curve (Fig. 3) was found to be linear hence the acid degradation follows the first order. The results are shown in the table 6.

From the graph the rate constant was calculated using equation: Slope $=-\mathrm{K} / 2.303$. The rate constant was found to be 0.1082

\section{Degradation kinetic study under alkaline condition, $0.1 \mathrm{~N} N \mathrm{NaH}$}

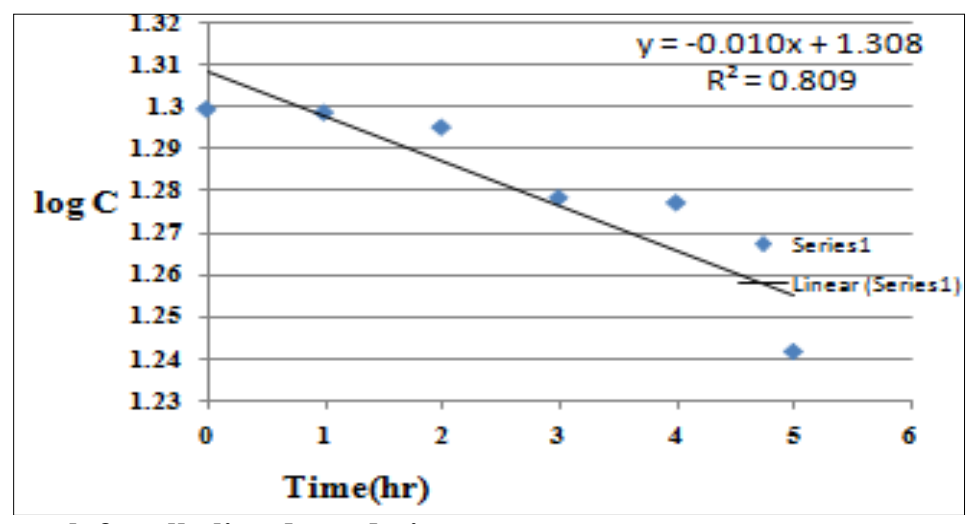

Fig. 4: Log C vs. time graph for alkaline degradation.

Degradation kinetic study of bulk drug under alkaline condition at room temperature showed that the decrease in area for each sample withdrawn at 0-5 hr. The plot of $\log \mathrm{C}$ vs. time curve (Fig. 4) was found to be linear (best fit for first order) and so the alkaline degradation follows the first order. The results are shown in the table 6.

From the graph the rate constant was calculated using equation: Slope $=-\mathrm{K} / 2.303$. The rate constant was found to be 0.023 .

\section{Degradation kinetic study under oxidative condition using $3 \% \mathrm{H}_{2} \mathrm{O}_{2}$}

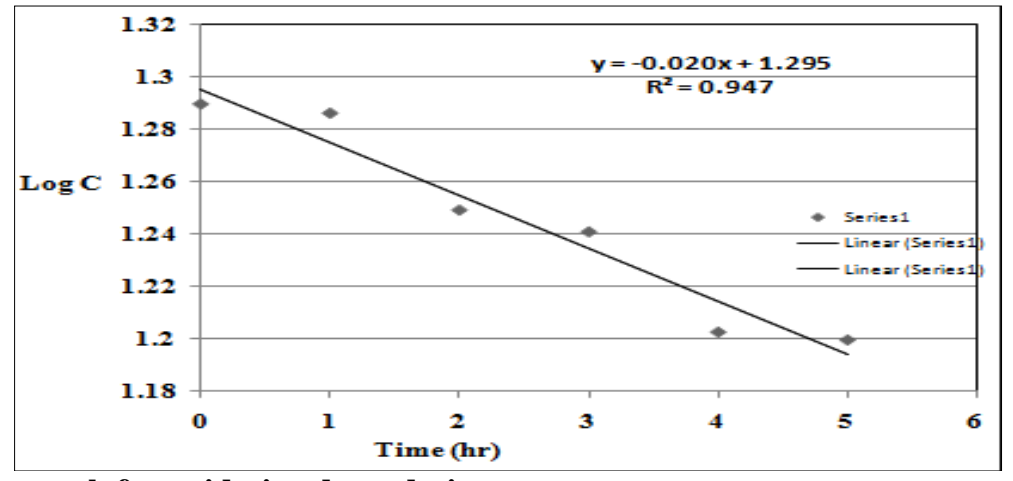

Fig. 5: Log C vs. time graph for oxidative degradation

Degradation kinetic study of bulk drug under oxidative condition at room temperature showed that the decrease in area for each sample withdrawn at 0-5 hr. The plot of $\log \mathrm{C}$ vs. time curve (Fig. 5) was found to be linear (best fit for first order) and so the oxidative degradation follows the first order. The results are shown in the table 6 . From the graph the rate constant was calculated using equation: Slope $=-\mathrm{K} / 2.303$. The rate constant was found to be 0.046 ,

Table 6: Degradation kinetic study of capecitabine, $\lambda_{\max } 240 \mathrm{~nm}$, Area of $20 \mu \mathrm{g} / \mathrm{ml}$ : 906348 (Comparison)

\begin{tabular}{|l|c|c|c|c|c|}
\hline $\begin{array}{c}\text { Degradation } \\
\text { Condition }\end{array}$ & $\begin{array}{c}\text { Time } \\
(\mathbf{h r})\end{array}$ & $\begin{array}{c}\text { Area } \\
(\boldsymbol{\mu V} \mathbf{~ s e c})\end{array}$ & $\begin{array}{c}\text { Conc. } \\
(\boldsymbol{\mu g} / \mathbf{m l})\end{array}$ & Log C & $\begin{array}{c}\text { Degradation rate constant } \\
\left(\mathbf{h r}^{-\mathbf{1}}\right)\end{array}$ \\
\hline $\begin{array}{l}\text { Degradation } \\
\text { kinetic study in }\end{array}$ & 0 & 864826 & 19.0837 & 1.2806 & - \\
\cline { 2 - 6 } $\mathrm{HCl} 0.1 \mathrm{~N}$ & 1 & 795649 & 17.5572 & 1.2444 & 2.5263 \\
\cline { 2 - 6 } & 2 & 696492 & 15.3691 & 1.1866 & 0.8184 \\
\cline { 2 - 6 } & 3 & 626227 & 13.8186 & 1.1404 & 0.4293 \\
\cline { 2 - 6 } & 4 & 536030 & 11.8283 & 1.0729 & 0.2418 \\
\hline
\end{tabular}




\begin{tabular}{|l|c|c|c|c|c|}
\hline & 5 & 518257 & 11.4361 & 1.0582 & 0.1829 \\
\hline \multirow{2}{*}{$\begin{array}{l}\text { Degradation } \\
\text { kinetic study in }\end{array} 0.1 \mathrm{~N} \mathrm{NaOH}$} & 0 & 903102 & 19.9283 & 1.2994 & - \\
\cline { 2 - 6 } & 1 & 901412 & 19.8910 & 1.2986 & 6.2822 \\
\cline { 2 - 6 } & 2 & 894217 & 19.7323 & 1.2951 & 2.3111 \\
\cline { 2 - 6 } & 3 & 860187 & 18.9813 & 1.2783 & 1.0157 \\
\cline { 2 - 6 } & 4 & 857827 & 18.9293 & 1.2771 & 0.7484 \\
\cline { 2 - 6 } & 5 & 790537 & 17.4444 & 1.2416 & 0.4165 \\
\hline $\begin{array}{l}\text { Degradation } \\
\text { kinetic study in } \\
3 \% \mathrm{H}_{2} \mathrm{O}_{2}\end{array}$ & 0 & 882841 & 19.4812 & 1.2896 & - \\
\cline { 2 - 6 } & 2 & 875685 & 19.3233 & 1.2860 & 4.8160 \\
\cline { 2 - 6 } & 3 & 804092 & 17.7435 & 1.2490 & 1.2086 \\
\cline { 2 - 6 } & 4 & 729002 & 17.4105 & 1.2408 & 0.7473 \\
\cline { 2 - 6 } & 5 & 717434 & 15.9413 & 1.2025 & 0.4264 \\
\hline
\end{tabular}

\section{Conclusion}

A simple, cost effective, specific, accurate and precise HPLC method has been developed which can be successfully useful in routine analysis in quality control laboratories for the determination of CPT in bulk drug and pharmaceutical formulation. The developed methods have been validated as per ICH guidelines, and it meets all the acceptance criteria given in ICH guidelines, thus it can be concluded that the method is validated. Degradation study showed that CPT was analyzed in all the stress conditions without interference of the excipients, impurities and degradation products thus this method can also be used as stability indicating assay method. Degradation pathway of Capecitabine was found to be the acid hydrolysis and temperature exceeding $100^{\circ} \mathrm{c}$. The acid hydrolysis is may be due to the presence of Carbamate group in the structure of a Capecitabine. The degraded product peaks were well resolved from the pure drug peak with significant difference in their retention time. Degradation kinetic study shows that CPT follows first order kinetic in acid hydrolysis, alkaline hydrolysis and oxidative condition.

\section{Acknowledgement}

The author is grateful to west coast pharma and Intas Pharma Pvt. Ltd. for providing gift sample. The author is highly grateful to Institute of Research and Development, Gujarat Forensic Sciences University, Sector 18/A, Near police bhavan, Gandhinagar382007, Gujarat, India for providing all the facilities to carry out the work.

\section{References}

1. XELODA PI 110125, CDS8.0, Page no.: 1-28, Roche.

2. Q1A (R2): stability testing of new drugs and products, International Conference on Harmonization of Technical Requirements for Registration of Pharmaceuticals for Human Use, ICH harmonised tripartite guideline, 2003, $1-18$.

3. FDA Guideline for Submitting Samples and Analytical Data for Methods Validation.

4. FDA Reviewer Guidance: Validation of Chromatographic Methods.
5. FDA guideline Guidance for Industry, Analytical Procedures and Methods Validation, FDA, 2000.

6. Swartz, M., Krull, I. Investigating Out-Of-Specifications Results. LCGC. 2004;22(2):132-136.

7. Centre for Drug Evaluation and Research (CDER). (2006). Guidance for Industry Investigating Out-ofSpecification (OOS) Test Results for Pharmaceutical Production. Accessed on April, 2011. Available from: <http://www.fda.gov/downloads/Drugs/GuidanceComplia nceRegulatoryInfor mation/Guidances/ucm070287.pdf>

8. Ana Paola Cione, Edivan Tonhi and Paulo Silva (2011). Stability Indicating Methods, Quality Control of Herbal Medicines and Related Areas, Prof. Yukihiro Shoyama (Ed.), ISBN: 978-953-307-682-9, InTech, Available from: http://www.intechopen.com/books/quality-controlof-herbal-medicines-and-related areas/stabilityindicatingmethods. pg no.: 25- 36.

9. Kapil Kalra, Method Development and Validation of Analytical Procedures, In Tech, www.intechopen.com, PAGE NO.: 1-15.

10. ICH Q2A. Guidance for industry: Text on validation of analytical procedures.2011.Available at: http://www.fda.gov/downloads/Drugs/GuidanceComplian ceRegulatoryInformation/Guidances/ucm073381.pdf

11. Cartenson JT, Swarbrick J. Solution kinetics- Drug stability principles and practice; 2nd Edn; Marcel Dekker series, 1995, pp 21-54.

12. Martin A., Swarbrick J., Cammarata A. Physical Pharmacy- Physical Chemical Principles in the Pharmaceutical Sciences; 4th Edn; Lippincott, Williams and Wilkins, 2001, pp 285-290.

13. Lachman L., Lieberman HA., Kanig JL. The Theory and Practice of Industrial Pharmacy; 3rd Edn; Varghese Publishing House, 1987, pp 760.

14. P Sankpal, R Doijad, G Suryawanshi, P Patil, A Pathan, simple quantitative method development and validation of capecitabine in pure form and pharmaceutical dosage form by uv-spectroscopy, Inventi Rapid: Pharm Analysis \& Quality Assurance.2012.

15. Medikondu Kishore, M. Jayaprakash, T. Vijayabhaskarareddy. International Journal of Chem Tech Research. Vol.3, No.1, Page no. 63-69.

16. Sreenivasa Rao T, Sukanya K, Chandanam Sreedhar, Akkamma HG, Sai Kumar S, Manogna, Development and Validation of New Analytical Methods for the Estimation of Capecitabine in Pharmaceutical Dosage Form, Research Journal of Pharmaceutical, Biological and Chemical Sciences. 2012;3(3):713-721. 
17. Mugunthu R. Dhananjeyan a, Jidong Liu a, Crystal Bykowski a, Jill A. Trendel a Jeffrey G. Sarver a, Howard Andob, Paul W. Erhardt. Journal of Chromatography A. 2007;1138:101-108.

18. K. Ravi Kumar1, CH. M.M. Prasada Rao, CH. Babu Rao1, K.B. Chandrasekhar. International Journal of Chem Tech Research. 2010;2(1):307-311.

19. Narendra Devanaboyina, Y. Sai Kishore, P. Pushpalatha, N. Mamatha, P. Venkatesh. International j of science invention today. Page no.21-30.

20. P. Ravisankar, G. Devala Rao, M. Naveen Kumar, M. Krishna Chaitanyarary, and Scholars Research Library, 2013;5(3):249-260.

21. Andre farkouh, Dagmar ettlinger, Johannes schueller, Apostolos Georgopoulos, Werner Scheithauer and Martin Czejka, Anticancer Research. 2010;30:5207-5212.
22. L. Zuf'1a, A. Aldaz, J. Giráldez, Simple determination of capecitabine and its metabolites by liquid chromatography with ultraviolet detection in a single injection. Journal of Chromatography B. 2004;809:5158.

23. Rajithakandimallai. Validated estimation of Capecitabine by HPTLC. IRJP. 2012;3(11):163-166.

24. Pani Kumar AD, Venkata Raju Y, Sunitha G, Rama Krishna K, Ceema M and Venkateshwara Rao A. Development of Validated Stability Indicating RP-HPLC Method for the estimation of Capecitabine in Pure and Pharmaceutical Formulations. International Journal of Research in Pharmaceutical and Biomedical Sciences. 2011;2(1):175-181. 